\title{
Stimuli-responsive hydrogels as a model of the dynamic cellular microenvironment
}

\author{
Motomu Tanaka $\mathbb{D}^{1,2} \cdot$ Masaki Nakahata $^{3} \cdot$ Philipp Linke $^{1} \cdot$ Stefan Kaufmann ${ }^{1}$
}

Received: 15 January 2020 / Revised: 13 March 2020 / Accepted: 1 April 2020 / Published online: 14 May 2020

(c) The Author(s) 2020. This article is published with open access

\begin{abstract}
Ample evidence has demonstrated that biological cells not only react to biochemical cues from the surrounding microenvironments but also sensitively detect the mechanical properties of the extracellular matrix and neighboring cells to adapt their shape, function, and fate. Mechanical aspects in biology, called mechanobiology, have been attracting biologists, chemists, physicists, and mechanical engineers. However, most in vitro studies to date have heavily relied on covalently cross-linked hydrogels with prefixed and hence unchangeable mechanical properties, although the mechanical properties of the cellular microenvironment are never uniform or static. From this context, stimuli-responsive hydrogels are highly attractive as surrogate materials that can simulate dynamic physical microenvironments in vivo. This review tries to provide a comprehensive overview of previous achievements, present pitfalls and challenges, and future perspectives on the recent development of stimuli-responsive hydrogel materials for the dynamic control of cell behavior.
\end{abstract}

\section{Introduction}

During the past two decades, mechanobiology has drawn increasing attention as an interdisciplinary forum for researchers from the fields of materials science and biomedical science. Mounting evidence suggests that biological cells not only passively sense biochemical cues but also actively react to mechanical cues from the surrounding microenvironment [1, 2]. For example, the formation of neurite branches of neuronal cells [3] and the striation of actomyosin bundles in cardiac myotubes [4] is significantly improved on hydrogel substrates possessing elastic moduli comparable to those of the native extracellular matrix. Researchers from regenerative medicine have also suggested

Motomu Tanaka

tanaka@uni-heidelberg.de

$\triangle$ Masaki Nakahata

nakahata@cheng.es.osaka-u.ac.jp

1 Physical Chemistry of Biosystems, Institute of Physical Chemistry, Heidelberg University, 69120 Heidelberg, Germany

2 Center for Integrative Medicine and Medicine, Institute for Advanced Study, Kyoto University, Kyoto 606-8501, Japan

3 Department of Materials Engineering Science, Graduate School of Engineering Science, Osaka University, Osaka 560-8531, Japan the importance of mechanical compliance in the regulation of stem cell differentiation. Mesenchymal stem cells injected into the blood vessels of a lever undergoing fibrosis did not lead to the regeneration of hepatocytes but instead led to misdifferentiation into ductal cells [5]. In 2006, Discher and coworkers showed that the lineage-specific differentiation of somatic stem cells can be regulated by the elasticity of chemically cross-linked polyacrylamide substrates functionalized with type I collagen [6]. Although later studies have shown that substrate elasticity is important but not the only determinant for the fate of stem cells [7, 8], this study made many materials scientists aware of the crucial roles of mechanics in regulating cells. To date, a number of chemically cross-linked hydrogels have been synthesized as models of the extracellular matrix [9]. The fine adjustment of cross-linker concentrations and the reaction time $[10,11]$ enables the control of bulk elastic moduli (Young's moduli) of hydrogels ex situ. Such materials have been used to gain insights into the roles of elasticity compliance between cells and the extracellular matrix in optimizing cell morphology [4, 12, 13], regulating migratory behavior [14, 15], controlling stem cell differentiation [16], and engineering tissue [17].

However, these ex situ approaches to mechanically regulate biological cells have overlooked one key aspect: the microenvironments of cells are never static but highly dynamic. Dynamic changes in extracellular matrix stiffness significantly influences various cellular functions. A number of studies have 


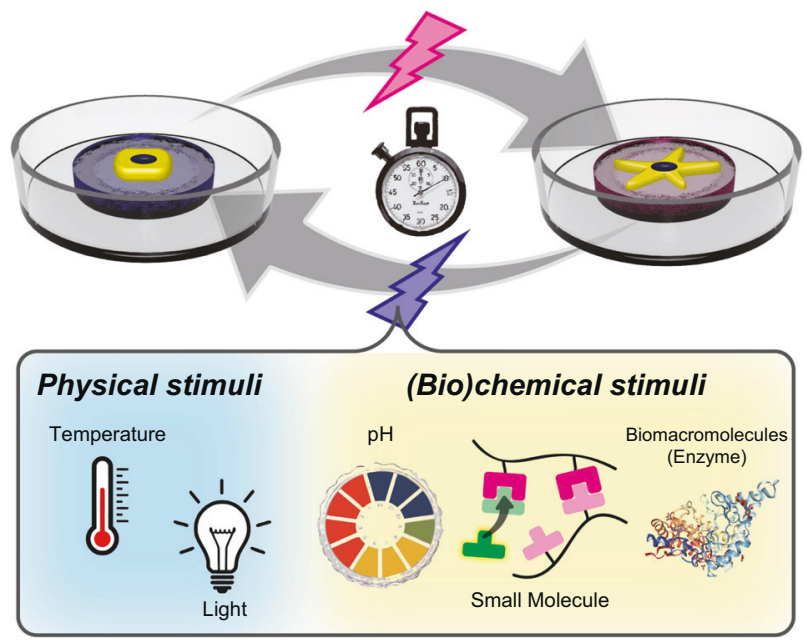

Fig. 1 Dynamic regulation of cells using materials with mechanical properties that can be altered in response to cytocompatible external stimuli

shown that remodeling of the extracellular matrix is prominent in many diseases. For example, hematopoietic diseases, such as leukemia and osteomyeloma, are accompanied by the fibrotic stiffening of bone marrow, resulting in cytopenia [18]. It has also been shown that enzymatic degradation of hyaluronic acid is enhanced during tumor growth and inflammation [19]. All these findings indicate a clear demand to design a new class of extracellular matrix models whose mechanical properties can be modulated on demand by external stimuli (Fig. 1). In this review, we will highlight recent progress in the design of stimuli-responsive hydrogel materials for the dynamic regulation of cellular functions.

\section{(Bio)chemical modulation of covalently cross-linked hydrogels}

One straightforward strategy to change the mechanical properties of cellular microenvironments is to follow the tactics of cancer cells, i.e., enzymatic degradation. For example, a number of studies have shown that many metastatic cancers can be characterized by the overproduction of various matrix metalloproteases that digest extracellular matrix proteins [20]. The enzymatic digestion of extracellular polysaccharides, such as hyaluronic acid, exhibits a clear influence on the expression level of CD44 in various cancer cells [19]. Digestion of extracellular matrix by enzymes not only cuts biomacromolecules into smaller fragments but also reduces the density of the cross-links. This inspired material scientists to synthesize chemically or biochemically degradable hydrogel substrates. Yui et al. reported that hyaluronic acid cross-linked with glycidyl ether can be degraded by hydroxyl radicals in vitro and by inflammation in vivo [21]. Hyaluronic acid gels can be synthesized by cross-linking thiolated hyaluronic acid with poly(ethylene glycol) diacrylate [22], photopolymerizing hyaluronic acid modified with methacryloyl groups [23], or forming disulfide bonds between thiolated hyaluronic acid polymers [24, 25]. These gels can be degraded by either the biochemical degradation of hyaluronic acid backbones with hyaluronidase or the chemical cleavage of disulfide bridges with dithiothreitol.

Collagen and gelatin, which are both degraded by collagenase, have been used for various biomedical applications, such as the release of growth factors [26] and wound healing [27]. During the last two decades, many researchers have examined the combination of hyaluronic acid, collagen/gelatin, and other polymers for numerous biological and medical applications [28-30]. A similar strategy can also be applied to chemically cleave the covalent cross-links of hydrogels made out of synthetic polymers. For example, Kloxin et al. [31, 32] designed poly(ethylene glycol) hydrogels whose cross-linking can be cleaved by light. A unique but medically relevant strategy to cleave chemical cross-links is irradiation with gamma rays. Simmons et al. [33] reported that rat stromal cells implanted together with alginate hydrogels into severely immunodeficient mice exhibited high bone regeneration capacity by the fine adjustment of gamma ray irradiation, which can be attributed to the controlled release/diffusion of growth factors in the rapidly degrading, irradiated hydrogels. Chemical stiffening of hydrogel substrates during cell culture is more challenging because it often requires the formation of additional bonds under challenging conditions for cells, such as UV irradiation. Guvendiren and Burdick [34] proposed the use of methacrylated hyaluronic acid that can be cross-linked in two steps; the degree of the first crosslinking is controlled by the amount of dithiothreitol, whereas the remaining methacrylate groups can be crosslinked by UV irradiation. Nevertheless, it should be noted that the conditions for these stimuli must be examined very carefully in advance because it has been reported that dithiothreitol makes the bacterial cell walls porous [35], and over-irradiation of cells by UV light is known to cause apoptosis [36]. A recent account has shown that the enzymatic reaction followed by photochemical cross-linking of hyaluronic acid derivatives can also be used to stiffen hydrogels on demand [37].

\section{Thermal modulation of hydrogels}

Another useful cue to modulate the mechanical properties of polymeric materials is temperature. If one considers the applications in bioscience, one of the most widely used synthetic thermoresponsive polymers is poly( $N$-isopropylacrylamide) (PNIPAAm) [38]. In aqueous media, PNIPAAm undergoes a 
Fig. 2 a Changes in the polymer chain conformation at a lower critical solution temperature (LCST) is driven by the not energetically favored mixing entropy. b Phase diagram of an LCST polymer. c Cell sheet detachment from a thermoresponsive surface coated with the LCST polymer

(a)

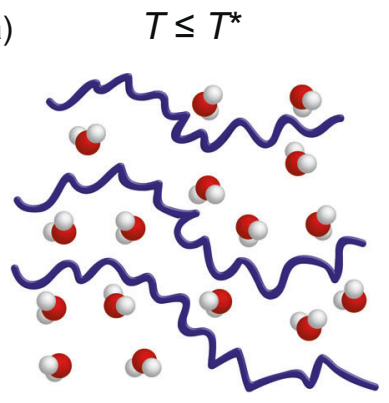

Miscible (water-soluble)
$T \geq T^{*}$

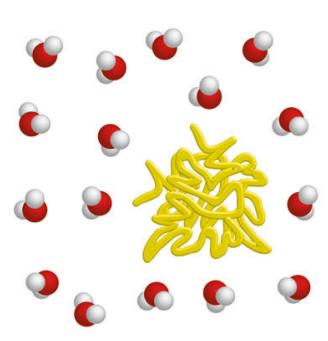

Phase separated (water-insoluble)

(b)

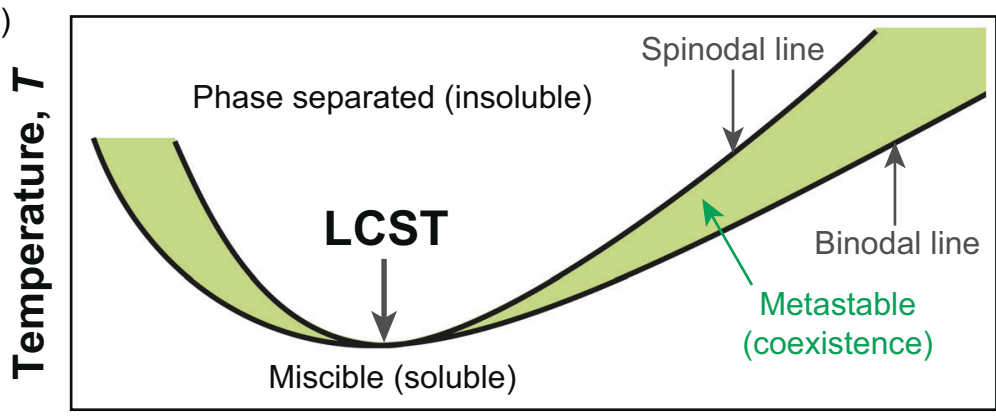

Fraction, $X$

(c)
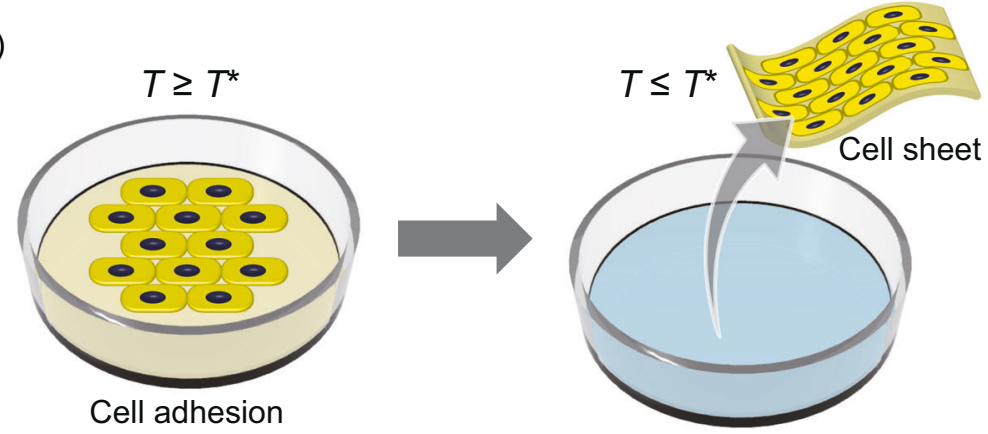

coil-to-globule transition at $T^{*}=32-33{ }^{\circ} \mathrm{C}$. As shown schematically in Fig. 2a, PNIPAAm is insoluble in aqueous media at $T \geq T^{*}$, taking on a collapsed coil conformation. On the other hand, when $T \leq T^{*}$, PNIPAAm becomes water soluble and takes on a globular conformation. From a thermodynamic viewpoint, the lower critical solution temperature $T^{*}$ (LCST) can generally be understood as the difference in the free energy change caused by mixing water with the polymer. As shown in Fig. 2b, the local stability of polymer-water mixtures can be defined by a spinodal line, which corresponds to $\frac{\partial^{2} G}{\partial x^{2}}=0$. The conditions inside the curve will undergo spinodal decomposition (phase separation). On the other hand, the binodal line indicates the conditions for phase coexistence. As the mixing of polymer and water is spontaneous at $T \leq T^{*}, \Delta G_{m i x} \leq 0$ at $T \leq T^{*}$, whereas $\Delta G_{m i x} \geq 0$ at $T \geq T^{*}$. Poorly water soluble, compact PNIPAAm is stiff and thus allows cell adhesion at $T \geq T^{*}$. On the other hand, PNIPAAm dissolves in water at
$T \leq T^{*}$, which results in cell detachment. Okano and coworkers prepared PNIPAAm hydrogels on the surface of culture dishes by electron beam-induced polymerization, cultured cells at $T \geq T^{*}\left(37^{\circ} \mathrm{C}\right)$ to confluency, and detached a cell monolayer from the culture dishes by lowering the temperature to $T \leq T^{*}$ (Fig. 2c) [39, 40]. This launched the large potential to harvest a two-dimensional sheet of cells without proteolytic dissociation so that one can directly transplant the cell sheet [41, 42].

Block copolymers of poly(ethylene oxide) (PEO) and poly(propylene oxide) (PPO) possess unique thermoresponsive properties, whose LCST can be adjusted to between 20 and $85^{\circ} \mathrm{C}$ simply by changing the composition of each block [43, 44]. The aqueous solutions undergo a sol-gel transition when heated above the LCST. Some block copolymers, such as pluronics, poloxamers, and tetronics, are commercially available and used as injectable polymer therapeutics for the controlled release of proteins, 
drugs, and genes [45, 46]. For example, pluronic F-127, $(\mathrm{PEO})_{106}(\mathrm{PPO})_{70}(\mathrm{PEO})_{106}$, can be dissolved as a clear solution of micelles at low temperature but turn into stiff gels at body temperature. Upon injection into the body, they can form protective barriers without losing the capacity to release functional entities [43, 47]. Pluronics have also been used as materials to reduce cell adhesion [48] as well as improve blood compatibility [49].

\section{pH modulation of hydrogels}

The extracellular pH level near a tumor is distinctly lower than that near normal, healthy tissue [50]. On the other hand, the intracellular $\mathrm{pH}$ of cancer cells is higher than the $\mathrm{pH}$ inside normal cells [51]. Such a reversed $\mathrm{pH}$ gradient in cancer cells and normal cells suggests that both the efficacy of drugs and the release of drugs from carriers strongly depend on the $\mathrm{pH}$. Therefore, $\mathrm{pH}$-responsive hydrogels have drawn attention as tailor-made carriers for anticancer drugs owing to their capability to release drug molecules selectively at a certain $\mathrm{pH}$ values $[52,53]$. Anionic polyelectrolytes, such as poly(acrylic acid) and poly(methacrylic acid), have been investigated in pharmaceutical applications, as they reversibly alter the degree of ionization at acidic $\mathrm{pH}$ values $[54,55]$.

To modulate the micromechanical environment of cells without interfering with their $\mathrm{pH}$ viability and functionality, weak polyelectrolytes seem more advantageous compared with strong polyelectrolytes because the degree of ionization can be adjusted near physiological $\mathrm{pH}$. A prominent example inspired by nature is block copolymers containing polypeptides consisting of naturally occurring, weakly acidic/basic amino acids [56, 57]. Tailor-made oligo- and polypeptides both enable the flexible adjustment of isoelectric points. By using secondary structures, such as $\alpha$-helices [58], these block copolymers can self-assemble into a variety of superstructures, such as micelles [59] and vesicles [60].

Among synthetic polymers possessing $\mathrm{pKa}$ values in the range of 6.3-7.5, poly(2-(alkylamino)ethyl methacrylate) derivatives have been utilized to fabricate various biomaterials [61]. Armes and coworkers synthesized a variety of block copolymers containing these moieties by means of reversibledeactivation radical polymerization, such as atom transfer radical polymerization and reversible addition-fragmentation chain transfer polymerization. They reported that some of the block copolymers are able to form highly uniform and stable micelles [62, 63]. Block copolymers consisting of a $\mathrm{pH}-$ sensitive block and a biocompatible zwitterionic poly(2(methacryloyloxy)ethyl phosphorylcholine) (PMPC) block $[64,65]$ enable the fabrication of biocompatible and $\mathrm{pH}-$ responsive micelles [62], vesicles [66], and free-standing gels [67] under physiological conditions.
By choosing the optimal block ratio, monolayers [68] and hydrogels [69] on solid substrates can also be formed. For example, specular neutron reflectivity data confirmed that a few nanometer-thick monolayer of a block copolymer showed distinct switching of the film thickness by the reversible charging/decharging of $\mathrm{pH}$-responsive blocks. This further enables one to reversibly switch the thickness of the water layer between a lipid membrane and the underlying substrate by a factor of almost 2 [68]. However, a few nanometer-thick monolayer system is not suited for regulation of cells because cells mechanically "feel" the underlying solid substrates possessing an elastic modulus of $\sim 1 \mathrm{GPa}$. As the strain field caused by the active traction force generated by cells decays exponentially over the distance from the surface, the use of hydrogels with thicknesses larger than $1 \mu \mathrm{m}$ is necessary to ensure that the cells feel substrate elasticity [70]. Hydrogel films of the block copolymer composed of $\mathrm{pH}$-responsive and PMPC blocks can be prepared by spin-coating of methanolic solutions. After the removal of methanol, the films can be soaked and hydrated in cell culture medium. The basic building blocks of this hydrogel are formed by the physical entanglement of "flower-like" micelles of pH-responsive poly(2-(isopropylamino)ethyl methacrylate) (PDPA) surrounded by biocompatible PMPC blocks (Fig. 3a). As the pKa of the protonated PDPA homopolymer is $\sim 6.2$ [61], the mean degree of ionization of the PDPA core is lower at higher $\mathrm{pH}$. The uncharged PDPA core is more compact owing to less intrachain electrostatic repulsion compared with the charged core, which results in a larger bulk elastic modulus. On the other hand, upon lowering the $\mathrm{pH}$, the interaction between partially charged PDPA blocks becomes more repulsive, which results in a softer gel film. As the bulk elastic modulus of the gel is linearly proportional to $\mathrm{pH}$, it is possible to reversibly soften and stiffen the hydrogel substrates between $1.4 \mathrm{kPa}$ and $40 \mathrm{kPa}$ by simply adjusting the $\mathrm{pH}$ of the culture medium between 7 and 8 . Changes in the mechanical properties of contact substrates are sensed by the mechanotransduction machinery in focal adhesion complexes, which results in reversible changes in cell shape and adhesion strength without interference with cell viability (Fig. 3b) [69]. Cellular mechanosensing can be quantitatively parameterized by using the nematic order parameter of the actin cytoskeleton, $S=\cos 2 \theta$, where $\theta$ is the angle between the major axis of the cell and each actin filament [71]. Inoue et al. demonstrated that the abrupt softening of hydrogel substrates leads to a discontinuous decrease in the nematic order parameter of $\mathrm{C} 2 \mathrm{C} 12$ cytoskeletons, suggesting that dynamic cytoskeletal remodeling can be described physically as a break of symmetry, as in quantum mechanics [72].

These hydrogel substrates can also be used for the longterm maintenance of more naive cells, such as human 
(a)

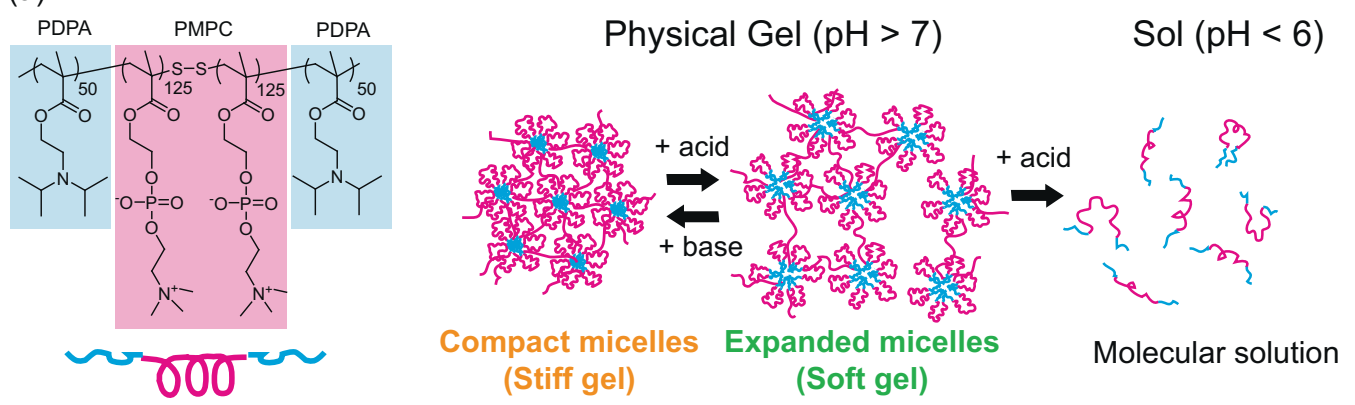

(b)

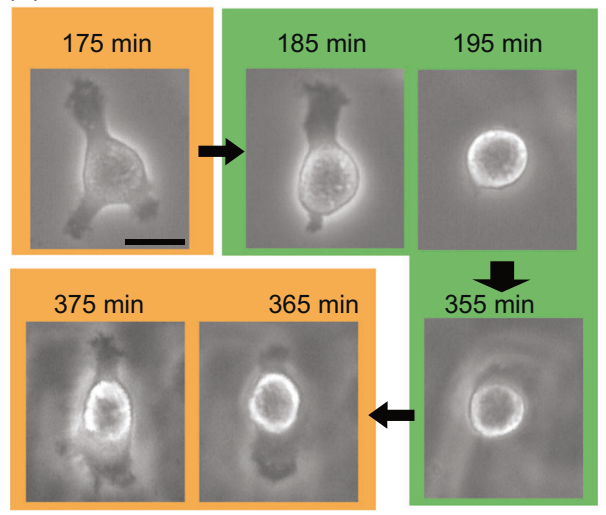

Fig. 3 a ABA triblock copolymer containing the $\mathrm{pH}$-responsive poly (2-(isopropylamino)ethyl methacrylate) (PDPA) block and biocompatible zwitterionic poly(2-(methacryloyloxy)ethyl phosphorylcholine) (PMPC) block. Physical entanglement of flower micelles results in $\mathrm{pH}$-responsive hydrogels. b Reversible switching of

mesenchymal stem cells (hMSCs) derived from the bone marrow [7]. More than $90 \%$ of the mesenchymal stem cells cultured on hydrogel substrates remain immunoreactive to the multipotency marker over $20 \mathrm{~d}$ irrespective of the substrate elasticity, suggesting that substrate elasticity is not the only factor determining stem cell fate. Once these cultured hMSCs are transferred into differentiation induction media at $t=20 \mathrm{~d}$, they can still undergo lineage-specific commitment to either adipocytes or osteoblasts. More remarkably, simply by changing the substrate elasticity every second day, the proliferation of hMSCs was significantly suppressed by up to $90 \%$ with no loss of the multiple lineage potential. However, although the modulation of $\mathrm{pH}$ does not interfere with the viability of stem cells, a new class of stimuli-responsive hydrogels that reversibly alter elasticity at physiological $\mathrm{pH}$ is safer and more useful for biomedical applications.

\section{Chemical modulation of hydrogels cross- linked by noncovalent bonds}

Many biomolecules self-assemble and build hierarchical structures via the interplay of noncovalent and hence

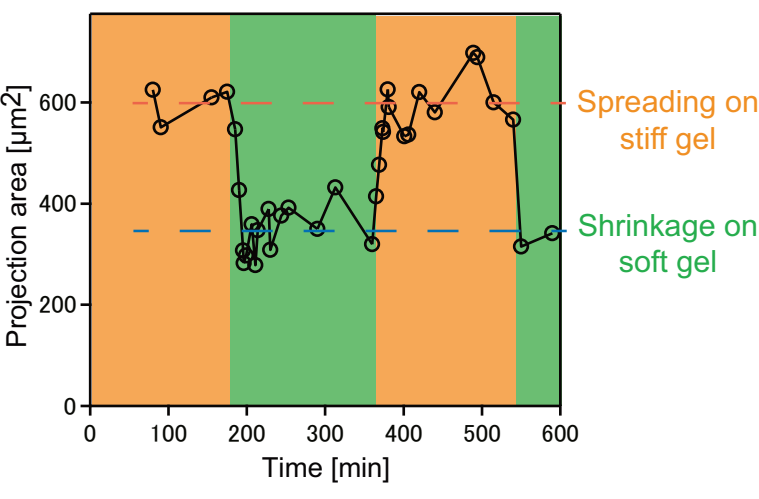

myoblast cells by the softening and stiffening of hydrogel substrates. Cells are contractile and spread on stiff substrates by gripping the substrates, but they take a round shape when the substrate elasticity is reduced from $40 \mathrm{kPa}$ to $2 \mathrm{kPa}$

reversible intermolecular interactions. This inspired materials scientists to design a new class of supramolecular polymers $[73,74]$, which are held together via reversible and highly directional noncovalent interactions, such as hydrogen bonding and host-guest interactions [75, 76]. For example, by modifying the side chains of the hosts and their complementary guest moieties, various hydrogels can be fabricated by cross-linking hydrophilic polymer chains via noncovalent, host-guest interactions. One of the unique characteristics of supramolecular hydrogels is that host-guest pairs can reversibly dissociate/associate by adding/removing competitive host (or guest) molecules to/ from the solution (Fig. 4a). For example, cyclodextrins (CDs) can serve as hosts that recognize hydrophobic, organic guest molecules in aqueous solutions [77]. Such reversible, noncovalent host-guest interactions recognize materials with highly unique functionalities, such as selfhealing of defects [78], repetitive contraction/expansion cycles [79], and tunable shear thinning capacity [80].

For the dynamic modulation of cellular micromechanical environments, supramolecular hydrogels can potentially provide an advantage over other stimuli-responsive hydrogels [80-82]. Compared with other stimuli, e.g., proteases, reducing agents, light, temperature, and $\mathrm{pH}$, one can 
Fig. 4 a Working principle of supramolecular hydrogels crosslinked via host-guest interactions. b The decrease in the bulk elastic modulus is linearly proportional to the $\log C$ of host/guest molecules dissolved in the medium. c Discrete and reversible control of myoblast cells on the same substrate incubated with media containing different amounts of free competitors (a)

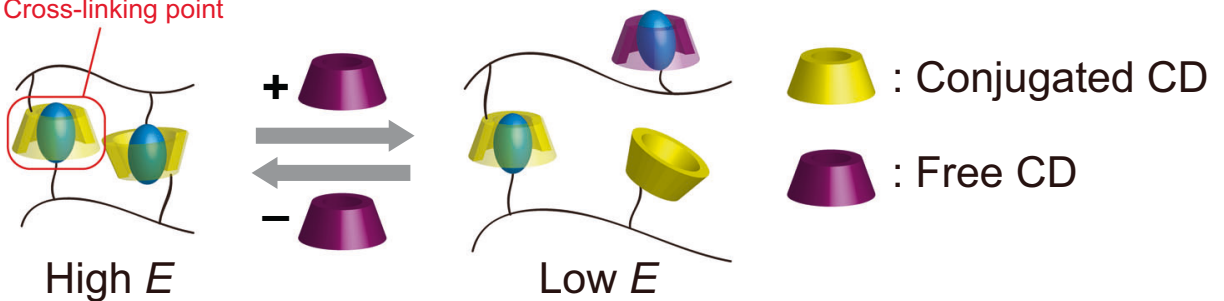

(b)

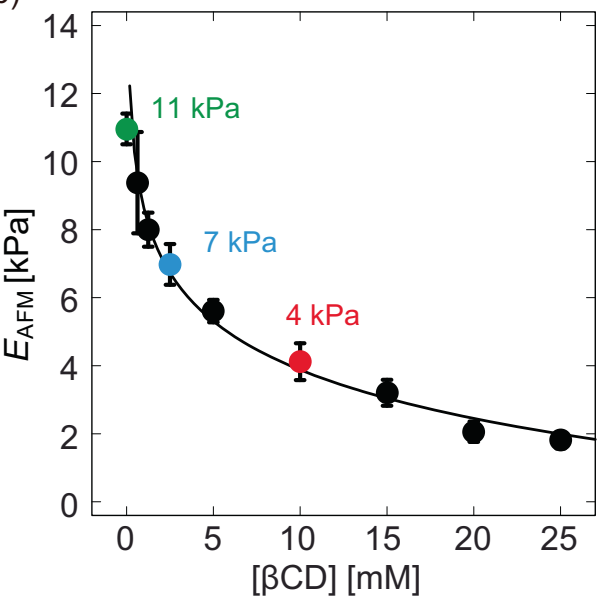

(c)

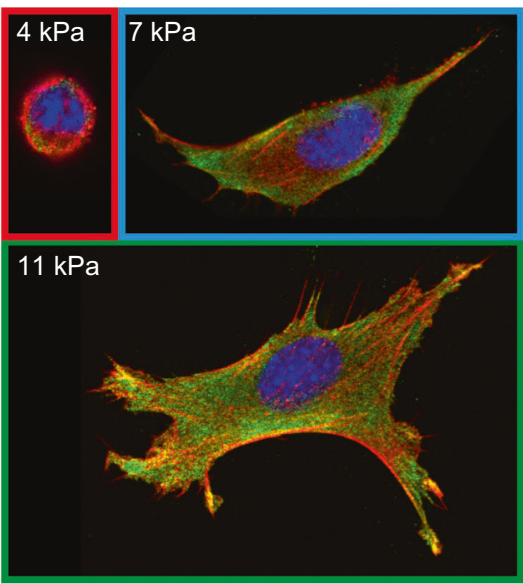

eliminate or minimize the risk of damaging cells by choosing host or guest molecules with no or little cytotoxicity. For example, hydrogels cross-linked with host-guest interactions between $\beta$-cyclodextrin $(\beta C D)$ and adamantane have been used for the dynamic regulation of myoblast cells [83]. First, the initial substrate elasticity can be optimized by selecting the molar fraction of host and guest monomers for the target cells. By varying the concentrations of free, competing host molecules $(\beta C D)$ in solution, the reversible nature of host-guest interactions enables us to flexibly adjust the extent of softening/stiffening of the hydrogel substrates. Compared with other stimuli-responsive materials that can either change the elasticity only in one direction or those that rely on lessbiocompatible stimuli such as UV light and temperature changes, supramolecular hydrogels enable the reversible application of mechanical cues without interfering with cell viability. The absolute level of the elastic modulus can be adjusted by the total monomer concentration and the mixing ratio between pure (matrix) acrylamide monomers and acrylamide monomers modified with host/guest moieties. $\beta C D$ has been approved as a food additive by the FDA (US Food and Drug Administration) and adamantane is not digested by cells $[84,85]$. Free $\beta C D /$ adamantane molecules dissolved in culture medium would lead to a decrease in the number of cross-links within $10 \mathrm{~min}$ by shifting the chemical equilibrium. This enables one to switch the substrate elasticity to the desired level at any time point merely by medium exchange; the decrease in elastic modulus is proportional to the chemical potential of free molecules and hence proportional to $\log [\beta C D /$ adamantane $]$ (Fig. 4b). On the other hand, after soaking hydrogels in normal medium with no additives, the substrate elasticity recovers to the original level within $1 \mathrm{~h}$. In the case of a hydrogel prepared with a total monomer concentration of $2 \mathrm{~mol} \mathrm{~kg}^{-1}$ containing $2.5 \mathrm{~mol} \%$ monomers with host/guest side chain functionalities, the substrate elasticity can be fine adjusted to between 11 and $4 \mathrm{kPa}$. The elastic modulus covered by this material was suited for both static (ex situ) and dynamic (in situ) regulation of cell morphology and cytoskeletal ordering of myoblasts (Fig. 4c) [83].

\section{Perspectives: from 2D to 3D, from isotropic to anisotropic}

As shown above, stimuli-responsive hydrogel materials enable dynamic modulation of the micromechanical environment of biological cells. This becomes highly relevant in simulating the remodeling of extracellular matrix caused by diseases and aging. For biomedical studies, the choice of stimuli that can change the substrate stiffness with minimal interference to cellular functions is extremely crucial. Compared with other hydrogels that are responsive to 
temperature, light, $\mathrm{pH}$, and enzymes, supramolecular hydrogels can potentially offer a larger degree of freedom in the choice of additives.

One natural and straightforward extension of such a strategy moves towards the development of threedimensional cellular environments with dynamically tunable mechanical properties, modeling in vivo cellular microenvironments. Recent studies have suggested that some types of cells cultured on two-dimensional substrates do not recapitulate the phenotype of the cells in vivo [86, 87]. To date, gelatin-based materials, such as Matrigel, have been used as three-dimensional cell culture materials, and other three-dimensional culture materials based on hydrogels are currently being developed [88].

Another interesting direction is to introduce anisotropy to the model of the extracellular matrix. In our body, fibrous extracellular matrix proteins, such as collagen, often exhibit a highly anisotropic topography that dictates the morphology, directional order, and migration of cells, called contact guidance [89-92]. As nanofibers of proteins, such as collagen and gelatin, have been utilized for various applications, including wound healing and tissue engineering [88, 93, 94], protein nanofibers with stimuli-responsive functional groups seem to be a promising and biologically relevant target. Moreover, fabrication of stimuli-responsive, three-dimensional microstructures comparable to or smaller than the size of cells with advanced three-dimensional printing technology is a promising strategy to microfabricate cellular scaffolds with a defined geometry [95].

The combination of stimuli-responsive hydrogels, protein fibers, and three-dimensional scaffolds not only helps us to understand how cells react to changes in complex environments but also realizes a new class of cell culture materials with tunable mechanical properties in a welldefined geometry.

Acknowledgements M.T., P.L., and S.K. thank the German Science Foundation (Collaborative Research Center CRC873 Project B7, SPP2171 and Germany's Excellence Strategy-2082/1-390761711) for support. M.T. and M.N. thank A. Harada and Y. Takashima (Osaka University) for stimulating discussions and the JSPS (KAKENHI grant numbers 17H00855, 18K14284, and 19H05719) for support. P.L. thanks the German-Japanese University Network (HeKKSaGOn alliance) for the fellowship. M.T. thanks the Nakatani Foundation for support.

Funding Open access funding provided by Projekt DEAL.

\section{Compliance with ethical standards}

Conflict of interest The authors declare that they have no conflict of interest.

Publisher's note Springer Nature remains neutral with regard to jurisdictional claims in published maps and institutional affiliations.
Open Access This article is licensed under a Creative Commons Attribution 4.0 International License, which permits use, sharing, adaptation, distribution and reproduction in any medium or format, as long as you give appropriate credit to the original author(s) and the source, provide a link to the Creative Commons license, and indicate if changes were made. The images or other third party material in this article are included in the article's Creative Commons license, unless indicated otherwise in a credit line to the material. If material is not included in the article's Creative Commons license and your intended use is not permitted by statutory regulation or exceeds the permitted use, you will need to obtain permission directly from the copyright holder. To view a copy of this license, visit http://creativecommons. org/licenses/by/4.0/.

\section{References}

1. Discher DE, Janmey P, Wang Y-1. Tissue cells feel and respond to the stiffness of their substrate. Science 2005;310:1139-43.

2. Vogel V, Sheetz M. Local force and geometry sensing regulate cell functions. Nat Rev Mol Cell Biol 2006;7:265-75.

3. Flanagan LA, Ju Y-E, Marg B, Osterfield M, Janmey PA. Neurite branching on deformable substrates. Neuroreport 2002;13:2411.

4. Engler AJ, Griffin MA, Sen S, Bönnemann CG, Sweeney HL, Discher DE. Myotubes differentiate optimally on substrates with tissue-like stiffness: pathological implications for soft or stiff microenvironments. J Cell Biol 2004;166:877-87.

5. Kanazawa H, Fujimoto Y, Teratani T, Iwasaki J, Kasahara N, Negishi K, et al. Bone marrow-derived mesenchymal stem cells ameliorate hepatic ischemia reperfusion injury in a rat model. PLoS One 2011;6:e19195.

6. Engler AJ, Sen S, Sweeney HL, Discher DE. Matrix elasticity directs stem cell lineage specification. Cell 2006;126:677-89.

7. Frank V, Kaufmann S, Wright R, Horn P, Yoshikawa HY, Wuchter P, et al. Frequent mechanical stress suppresses proliferation of mesenchymal stem cells from human bone marrow without loss of multipotency. Sci Rep. 2016;6:24264.

8. Trappmann B, Gautrot JE, Connelly JT, Strange DGT, Li Y, Oyen ML, et al. Extracellular-matrix tethering regulates stem-cell fate. Nat Mater 2012;11:642-49.

9. Rosales AM, Anseth KS. The design of reversible hydrogels to capture extracellular matrix dynamics. Nat Rev Mater 2016;1:15012.

10. Wen JH, Vincent LG, Fuhrmann A, Choi YS, Hribar KC, TaylorWeiner $\mathrm{H}$, et al. Interplay of matrix stiffness and protein tethering in stem cell differentiation. Nat Mater 2014;13:979-87.

11. Kidoaki S, Matsuda T. Microelastic gradient gelatinous gels to induce cellular mechanotaxis. J Biotech 2008;133:225-30.

12. Engler A, Bacakova L, Newman C, Hategan A, Griffin M, Discher D. Substrate compliance versus ligand density in cell on gel responses. Biophys J 2004;86:617-28.

13. Ghajar CM, Chen X, Harris JW, Suresh V, Hughes CCW, Jeon $\mathrm{NL}$, et al. The effect of matrix density on the regulation of 3-d capillary morphogenesis. Biophys J 2008;94:1930-41.

14. Lo C-M, Wang H-B, Dembo M, Wang Y-l. Cell movement is guided by the rigidity of the substrate. Biophys J 2000;79:144-52.

15. Kawano T, Kidoaki S. Elasticity boundary conditions required for cell mechanotaxis on microelastically-patterned gels. Biomaterials 2011;32:2725-33.

16. Khetan S, Guvendiren M, Legant WR, Cohen DM, Chen CS, Burdick JA. Degradation-mediated cellular traction directs stem cell fate in covalently crosslinked three-dimensional hydrogels. Nat Mater 2013;12:458-65.

17. Drury JL, Mooney DJ. Hydrogels for tissue engineering: scaffold design variables and applications. Biomaterials 2003;24:4337-51. 
18. Lambertenghi-Deliliers G, Orazi A, Luksch R, Annaloro C, Soligo D. Myelodysplastic syndrome with increased marrow fibrosis: a distinct clinico-pathological entity. $\mathrm{Br}$ J Haematol 1991;78: 161-66.

19. Stern R. in Hyaluronan in Cancer Biology (ed Robert Stern) 207-20 (Academic Press, 2008).

20. Zucker S, Lysik RM, Zarrabi MH, Moll U. M(r) 92,000 type IV Collagenase is increased in plasma of patients with colon cancer and breast cancer. Cancer Res 1993;53:140-46.

21. Nobuhiko Y, Teruo O, Yasuhisa S. Inflammation responsive degradation of crosslinked hyaluronic acid gels. J Control Release 1992;22:105-16.

22. Rehfeldt F, Brown AEX, Raab M, Cai S, Zajac AL, Zemel A, et al. Hyaluronic acid matrices show matrix stiffness in 2D and 3D dictates cytoskeletal order and myosin-II phosphorylation within stem cells. Integr Biol 2012;4:422-30.

23. Burdick JA, Chung C, Jia X, Randolph MA, Langer R. Controlled degradation and mechanical behavior of photopolymerized hyaluronic acid networks. Biomacromolecules 2005;6:386-91.

24. Shu XZ, Liu Y, Luo Y, Roberts MC, Prestwich GD. Disulfide cross-linked hyaluronan hydrogels. Biomacromolecules 2002;3:1304-11.

25. Hahn SK, Park JK, Tomimatsu T, Shimoboji T. Synthesis and degradation test of hyaluronic acid hydrogels. Int J Biol Macromolecules 2007;40:374-80.

26. Tabata Y, Miyao M, Ozeki M, Ikada Y. Controlled release of vascular endothelial growth factor by use of collagen hydrogels. J Biomater Sci Polym Ed 2000;11:915-30.

27. Chattopadhyay S, Raines RT. Collagen-based biomaterials for wound healing. Biopolymers 2014;101:821-33.

28. Segura T, Anderson BC, Chung PH, Webber RE, Shull KR, Shea LD. Crosslinked hyaluronic acid hydrogels: a strategy to functionalize and pattern. Biomaterials 2005;26:359-71.

29. Zhang L, Li K, Xiao W, Zheng L, Xiao Y, Fan H, et al. Preparation of collagen-chondroitin sulfate-hyaluronic acid hybrid hydrogel scaffolds and cell compatibility in vitro. Carbohydr Polym 2011;84:118-25.

30. D Mark, AB Brigham, Lo Edward, Bendali Amel, Burdick JasonA, Khademhosseini Ali. Mechanically robust and bioadhesive collagen and photocrosslinkable hyaluronic acid semiinterpenetrating networks. Tissue Eng Part A 2009;15:1645-53.

31. Kloxin AM, Tibbitt MW, Anseth KS. Synthesis of photodegradable hydrogels as dynamically tunable cell culture platforms. Nat Protoc 2010;5:1867-87.

32. Yang C, Tibbitt MW, Basta L, Anseth KS. Mechanical memory and dosing influence stem cell fate. Nat Mater 2014;13:645-52.

33. Simmons CA, Alsberg E, Hsiong S, Kim WJ, Mooney DJ. Dual growth factor delivery and controlled scaffold degradation enhance in vivo bone formation by transplanted bone marrow stromal cells. Bone 2004;35:562-69.

34. Guvendiren M, Burdick JA. Stiffening hydrogels to probe shortand long-term cellular responses to dynamic mechanics. Nat Commun 2012;3:792.

35. De Nobel JG, Dijkers C, Hooijberg E, Klis FM. Increased cell wall porosity in saccharomyces cerevisiae after treatment with dithiothreitol or EDTA. Microbiology 1989;135:2077-84.

36. Kulms D, Schwarz T. Molecular mechanisms of UV-induced apoptosis. Photodermatol Photoimmunol Photomed 2000;16:195-201.

37. Liu H-Y, Korc M, Lin C-C. Biomimetic and enzyme-responsive dynamic hydrogels for studying cell-matrix interactions in pancreatic ductal adenocarcinoma. Biomaterials 2018;160:24-36.

38. Schild HG. Poly(N-isopropylacrylamide): experiment, theory and application. Prog Polym Sci 1992;17:163-249.

39. Okano T, Yamada N, Okuhara M, Sakai H, Sakurai Y. Mechanism of cell detachment from temperature-modulated, hydrophilichydrophobic polymer surfaces. Biomaterials 1995;16:297-303.
40. Kushida A, Yamato M, Konno C, Kikuchi A, Sakurai Y, Okano T. Decrease in culture temperature releases monolayer endothelial cell sheets together with deposited fibronectin matrix from temperature-responsive culture surfaces. J Biomed Mater Res 1999;45:355-62.

41. Shimizu T, Yamato M, Kikuchi A, Okano T. Cell sheet engineering for myocardial tissue reconstruction. Biomaterials 2003;24:2309-16.

42. Nishida K, Yamato M, Hayashida Y, Watanabe K, Yamamoto K, Adachi E, et al. Corneal reconstruction with tissue-engineered cell sheets composed of autologous oral mucosal epithelium. N. Engl J Med 2004;351:1187-96.

43. Schmolka IR. Artificial skin I. Preparation and properties of pluronic F-127 gels for treatment of burns. J Biomed Mater Res 1972;6:571-82.

44. Alexandridis P, Alan Hatton T. Poly(ethylene oxide)-poly(propylene oxide)-poly(ethylene oxide) block copolymer surfactants in aqueous solutions and at interfaces: thermodynamics, structure, dynamics, and modeling. Colloid Surf A Physicochem Eng Asp 1995;96:1-46.

45. Kabanov AV, Batrakova EV, Alakhov VY. Pluronic ${ }^{\circledR}$ block copolymers as novel polymer therapeutics for drug and gene delivery. J Control Release 2002;82:189-212.

46. Escobar-Chávez JJ, López-Cervantes M, Naik A, Kalia Y, Quintanar-Guerrero D, Ganem-Quintanar A. Applications of thermo-reversible pluronic F-127 gels in pharmaceutical formulations. J Pharm Pharm Sci 2006;9:339-58.

47. Gilbert JC, Hadgraft J, Bye A, Brookes LG. Drug release from pluronic F-127 gels. Int J Pharm 1986;32:223-28.

48. Dewez JL, Lhoest JB, Detrait E, Berger V, Dupont-Gillain CC, Vincent LM, et al. Adhesion of mammalian cells to polymer surfaces: from physical chemistry of surfaces to selective adhesion on defined patterns. Biomaterials 1998;19:1441-45.

49. Mao C, Liang CX, Mao YQ, Li L, Hou XM, Shen J. Modification of polyethylene with Pluronics F127 for improvement of blood compatibility. Colloids Surf B: Biointerfaces 2009;74:362-65.

50. Wike-Hooley JL, Haveman J, Reinhold HS. The relevance of tumour $\mathrm{pH}$ to the treatment of malignant disease. Radiother Oncol 1984;2:343-66.

51. Gerweck LE, Seetharaman K. Cellular $\mathrm{pH}$ gradient in tumor versus normal tissue: potential exploitation for the treatment of cancer. Cancer Res 1996;56:1194-98.

52. Gupta P, Vermani K, Garg S. Hydrogels: from controlled release to $\mathrm{pH}$-responsive drug delivery. Drug Discov Today 2002;7:569-79.

53. Schmaljohann D. Thermo-and $\mathrm{pH}$-responsive polymers in drug delivery. Adv Drug Del Rev 2006;58:1655-70.

54. Donini C, Robinson DN, Colombo P, Giordano F, Peppas NA. Preparation of poly(methacrylic acid-g-poly(ethylene glycol)) nanospheres from methacrylic monomers for pharmaceutical applications. Int J Pharm 2002;245:83-91.

55. Kyriakides TR, Cheung CY, Murthy N, Bornstein P, Stayton PS, Hoffman AS. pH-Sensitive polymers that enhance intracellular drug delivery in vivo. J Control Release 2002;78:295-303.

56. Klok H-A, Lecommandoux S. Supramolecular materials via block copolymer self-assembly. Adv Mater 2001;13:1217-29.

57. Rodríguez-Hernández J, Chécot F, Gnanou Y, Lecommandoux S. Toward 'smart' nano-objects by self-assembly of block copolymers in solution. Prog Polym Sci 2005;30:691-724.

58. Cornelissen JJLM, Fischer M, Sommerdijk NAJM, Nolte RJM. Helical superstructures from charged poly(styrene)-poly(isocyanodipeptide) block copolymers. Science 1998;280:1427-30.

59. Rodríguez-Hernández J, Lecommandoux S. Reversible inside - out micellization of ph-responsive and water-soluble vesicles based on polypeptide diblock copolymers. J Am Chem Soc 2005;127:2026-27. 
60. Peters RJRW, Marguet M, Marais S, Fraaije MW, van Hest JCM, Lecommandoux S. Cascade reactions in multicompartmentalized polymersomes. Angew Chem Int Ed 2014;53:146-50.

61. Bütün V, Armes SP, Billingham NC. Synthesis and aqueous solution properties of near-monodisperse tertiary amine methacrylate homopolymers and diblock copolymers. Polymer 2001;42:5993-6008.

62. Ma Y, Tang Y, Billingham NC, Armes SP, Lewis AL, Lloyd AW, et al. Well-defined biocompatible block copolymers via atom transfer radical polymerization of 2-methacryloyloxyethyl phosphorylcholine in protic media. Macromolecules 2003;36:3475-84.

63. Warren NJ, Armes SP. Polymerization-induced self-assembly of block copolymer nano-objects via RAFT aqueous dispersion polymerization. J Am Chem Soc 2014;136:10174-85.

64. Ishihara K, Ueda T, Nakabayashi N. Preparation of phospholipid polylners and their properties as polymer hydrogel membranes. Polym J 1990;22:355-60.

65. Moro T, Takatori Y, Ishihara K, Konno T, Takigawa Y, Matsushita $\mathrm{T}$, et al. Surface grafting of artificial joints with a biocompatible polymer for preventing periprosthetic osteolysis. Nat Mater 2004;3:829-36.

66. Du J, Tang Y, Lewis AL, Armes SP. pH-sensitive vesicles based on a biocompatible zwitterionic diblock copolymer. J Am Chem Soc 2005;127:17982-83.

67. Castelletto V, Hamley IW, Ma Y, Bories-Azeau X, Armes SP, Lewis AL. Microstructure and physical properties of a phresponsive gel based on a novel biocomparostructure and physical properties of a ph-responsive gel based on a novel biocompatible ABA-type triblock copolymer. Langmuir 2004;20:4306-09.

68. Rehfeldt F, Steitz R, Armes SP, von Klitzing R, Gast AP, Tanaka M. Reversible activation of diblock copolymer monolayers at the interface by $\mathrm{pH}$ modulation, 1: lateral chain density and conformation. J Phys Chem B 2006;110:9171-76.

69. Yoshikawa HY, Rossetti FF, Kaufmann S, Kaindl T, Madsen J, Engel U, et al. Quantitative evaluation of mechanosensing of cells on dynamically tunable hydrogels. J Am Chem Soc 2011;133:1367-74.

70. Domke J, Radmacher M. Measuring the elastic properties of thin polymer films with the atomic force microscope. Langmuir 1998;14:3320-25.

71. Zemel A, Rehfeldt F, Brown AEX, Discher DE, Safran SA. Optimal matrix rigidity for stress-fibre polarization in stem cells. Nat Phys 2010;6:468-73.

72. Inoue S, Frank V, Hoerning M, Kaufmann S, Yoshikawa HY, Madsen J, et al. Live cell tracking of symmetry break in actin cytoskeleton triggered by abrupt changes in micromechanical environments. Biomater Sci 2015;3:1539-44.

73. Yang Z, Liang G, Wang L, Xu B. Using a kinase/phosphatase switch to regulate a supramolecular hydrogel and forming the supramolecular hydrogel in vivo. $\mathrm{J}$ Am Chem Soc 2006;128:3038-43.

74. Webber MJ, Appel EA, Meijer E, Langer R. Supramolecular biomaterials. Nat Mater 2016;15:13.

75. Brunsveld L, Folmer BJB, Meijer EW, Sijbesma RP. Supramolecular polymers. Chem Rev 2001;101:4071-98.

76. Harada A Supramolecular Polymer Chemistry. (Wiley, 2012).

77. Harada A, Takashima Y, Nakahata M. Supramolecular polymeric materials via cyclodextrin-guest interactions. Acc Chem Res 2014;47:2128-40.
78. Nakahata M, Takashima Y, Yamaguchi H, Harada A. Redoxresponsive self-healing materials formed from host-guest polymers. Nat Commun 2011;2:511.

79. Takashima Y, Hatanaka S, Otsubo M, Nakahata M, Kakuta T, Hashidzume A, et al. Expansion-contraction of photoresponsive artificial muscle regulated by host-guest interactions. Nat Commun 2012;3:1270.

80. Rodell CB, Kaminski AL, Burdick JA. Rational design of network properties in guest-host assembled and shear-thinning hyaluronic acid hydrogels. Biomacromolecules 2013;14:4125-34.

81. Wang W, Wang $\mathrm{H}$, Ren $\mathrm{C}$, Wang J, Tan M, Shen J, et al. A saccharide-based supramolecular hydrogel for cell culture. Carbohydr Res 2011;346:1013-17.

82. Liyanage W, Vats K, Rajbhandary A, Benoit DSW, Nilsson BL. Multicomponent dipeptide hydrogels as extracellular matrixmimetic scaffolds for cell culture applications. Chem Commun 2015;51:11260-63.

83. Hörning M, Nakahata M, Linke P, Yamamoto A, Veschgini M, Kaufmann S, et al. Dynamic mechano-regulation of myoblast cells on supramolecular hydrogels cross-linked by reversible host-guest interactions. Sci Rep. 2017;7:7660.

84. Stella VJ, He Q. Cyclodextrins. Toxicol Pathol 2008;36:30-42.

85. Spilovska K, Zemek F, Korabecny J, Nepovimova E, Soukup O, Windisch $\mathrm{M}$, et al. Adamantane - a lead structure for drugs in clinical practice. Curr Med Chem 2016;23:3245-66.

86. Derda R, Laromaine A, Mammoto A, Tang SKY, Mammoto T, Ingber DE, et al. Paper-supported 3D cell culture for tissue-based bioassays. Proc Natl Acad Sci 2009;106:18457-62.

87. Sun T, Jackson S, Haycock JW, MacNeil S. Culture of skin cells in $3 \mathrm{D}$ rather than $2 \mathrm{D}$ improves their ability to survive exposure to cytotoxic agents. J Biotech 2006;122:372-81.

88. Chen J-X, Cao L-J, Shi Y, Wang P, Chen J-H. In situ supramolecular hydrogel based on hyaluronic acid and dextran derivatives as cell scaffold. J Biomed Mater Res A 2016;104:2263-70.

89. Weiss P. Experiments on cell and axon orientation in vitro: the role of colloidal exudates in tissue organization. J Exp Zool 1945;100:353-86.

90. Flemming RG, Murphy CJ, Abrams GA, Goodman SL, Nealey PF. Effects of synthetic micro- and nano-structured surfaces on cell behavior. Biomaterials 1999;20:573-88.

91. Paul CD, Shea DJ, Mahoney MR, Chai A, Laney V, Hung W-C, et al. Interplay of the physical microenvironment, contact guidance, and intracellular signaling in cell decision making. FASEB J 2016;30:2161-70.

92. Linke P, Suzuki R, Yamamoto A, Nakahata M, Kengaku M, Fujiwara $\mathrm{T}$, et al. Dynamic contact guidance of myoblasts by feature size and reversible switching of substrate topography: orchestration of cell shape, orientation, and nematic ordering of actin cytoskeletons. Langmuir 2019;35:7538-51.

93. Chaudhuri O, Gu L, Darnell M, Klumpers D, Bencherif SA, Weaver JC, et al. Substrate stress relaxation regulates cell spreading. Nat Commun 2015;6:1-7.

94. Chaudhuri O, Gu L, Klumpers D, Darnell M, Bencherif SA, Weaver JC, et al. Hydrogels with tunable stress relaxation regulate stem cell fate and activity. Nat Mater 2016;15:326-34.

95. Hippler M, Blasco E, Qu J, Tanaka M, Barner-Kowollik C, Wegener M, et al. Controlling the shape of 3D microstructures by temperature and light. Nat Commun 2019;10:1-8. 


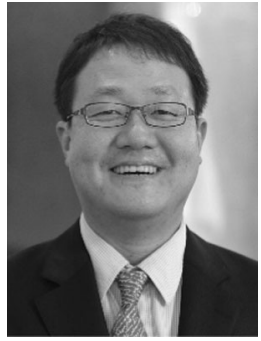

Motomu Tanaka received his PhD degree in physical chemistry from Kyoto University (Japan) in 1998, and joined the group of Erich Sackmann in the Department of Physics at Technical University of Munich (Germany) as the Fellow of JSPS and Humboldt Foundation. From 2001 to 2005, he led an independent research group at the TUM as an Emmy Noether Fellow, and received the Habilitation degree in experimental physics from the TUM. In 2005, Tanaka was appointed as a professor of chemistry and physics at Heidelberg University (Germany). Since 2013, he also leads a research group at Kyoto University. His research interests cover structure, mechanics and dynamics of biological interfaces, non-equilibrium physics of diseases and development, and their applications in material sciences.

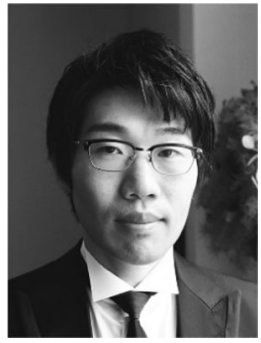

Masaki Nakahata received his PhD (2015) from the Graduate School of Science, Osaka University. Since 2016, he has been an assistant professor at the Graduate School of Engineering Science, Osaka University. His current research interests focus on the development of functional biomaterials based on supramolecular science and polymer science.

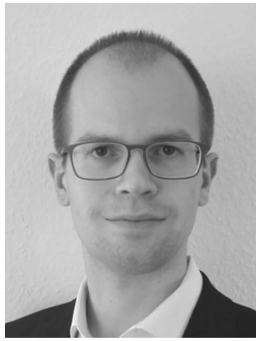

Philipp Linke studied physics at University of Göttingen (Germany) with a focus on biophysics, and obtained his MSc degree in physics in 2015. He then moved to Heidelberg University and joined Tanaka Lab as a PhD student. During his $\mathrm{PhD}$, he spent 1 year at Kyoto University (Japan) as a visiting scientist, supported by the Fellowship from the University Rector. His research interests cover dynamic adaptation of biological cells to stimuli far out of equilibrium and their impact on the fate of human stem cells. Currently, he focuses on the development of an artificial stem cell niche in collaboration with the Heidelberg University Hospital.

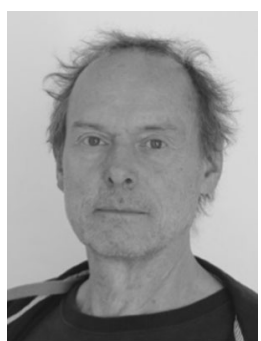

Stefan Kaufmann received his $\mathrm{PhD}$ degree in biology from Technical University of Munich (Germany) in 1993, and joined Nimbus GmbH as a researcher. In 2003, he joined the group of M. Tanaka at TUM as a staff scientist. Since 2007, he has been a senior group leader responsible for the biology laboratories in the Tanaka Lab at Heidelberg University (Germany). His research interests include biomembrane-based engineering and cell fate regulation using soft materials. 